\title{
Era uma vez dois irmãos...
}

\author{
MARCUS V. MAZZARI
}

Para Ecléa Bosi, que como Jacob Grimm voltou sua atenção às profundezas e à dignidade da velhice.

“A última colheita está no caule." (J. Grimm)

"O homem mais feliz é aquele que consegue relacionar o ocaso de sua vida ao início.”2 (J. W. v. Goethe)

$\mathrm{P}$ ATRIMÔNIO cultural de toda a humanidade, os “contos maravilhosos" (Märchen) dos irmãos Grimm ocupam certamente o primeiro lugar entre os textos alemães mais traduzidos. ${ }^{3}$ Inúmeros são os poetas e narradores que - desde Heinrich Heine, que em 1844 publica o longo poema satírico Deutschland. Ein Wintermärchen [Alemanha. Um conto maravilhoso de inverno], até Günter Grass - hauriram nessa fonte. Bertolt Brecht, por exemplo, ao expor num poema de juventude a "frieza" social pela perspectiva de um cavalo esquartejado em plena rua, alude ao cavalo falante "Falada" (ou, antes, apenas à cabeça deste, decepada e pendurada na viela sombria de uma cidade) e transpõe para o seu tempo outros motivos do pungente conto "A moça dos gansos". Referências e alusões a narrativas dos irmãos Grimm também não faltam na obra épica de Thomas Mann: são sete nos Buddenbrooks e seis no Doutor Fausto, para lembrar apenas o primeiro e o último de seus grandes romances. Essa influência é ainda mais expressiva em Günter Grass, nascido em outubro de 1927 na antiga cidade-livre de Danzig (a atual Gdańsk polonesa), prêmio Nobel em 1999 e certamente o mais proeminente nome da literatura alemã contemporânea. $O$ linguado (1977) desdobra em mais de 600 páginas a história, recolhida em dialeto pomerano, "O pescador e sua mulher" (Von dem Fischer un syner Fru); e no posterior romance $A$ ratazana (1986), Grass não apenas se vale de personagens como Joãozinho e Maria (Hänsel e Gretel, no original) para denunciar catástrofes ecológicas do século XX, como também faz dos próprios irmãos Jacob (1785-1863) e Wilhelm Grimm (1786-1859) personagens da trama romanesca. Mas já no Tambor de lata (1959), o romance de estreia que certamente ficará como sua obra mais famosa, o eu-narrador Oskar Matzerath, que subverte toda a tradição do "romance de formação e desenvolvimento" ao interromper o crescimento aos três anos de idade, conta-nos no capítulo "A tribuna" um acontecimento crucial de sua infância: o encontro, durante uma vesperal no Teatro Municipal de Danzig, com o Pequeno Polegar, saído diretamente do universo maravilhoso dos Grimm. ${ }^{5}$ 
E eis que, 51 anos mais tarde, os irmão Jacob e Wilhelm voltam a adentrar outro livro de Günter Grass. Mas agora não se trata dos infatigáveis compiladores das narrativas que viviam na tradição oral, mas sim dos Grimm de um projeto filológico verdadeiramente monumental. Pois Grimms Wörter [Palavras de Grimm], que Grass trouxe a lume pouco antes de completar 83 anos, narra em nove capítulos organizados pelas letras do alfabeto (primeiramente de A até F, e saltando depois para as letras $\mathrm{K}, \mathrm{U}$ e Z) os esforços dos irmãos Jacob e Wilhelm Grimm em elaborar um grande dicionário da língua alemã, apresentando a origem e etimologia de cada palavra - recuando, com frequência, ao gótico (gutiska razda: idioma falado pela tribo germânica dos godos) e ao antigo e médio alto-alemão (Althochdeutsch e Mittelhochdeutsch) -, a mudança das acepções ao longo dos séculos, assim como suas principais ocorrências na literatura, desde a Canção dos Nibelungos e outros "monumentos linguísticos" da Idade Média até a era de Goethe. ${ }^{6}$

Pode-se afirmar assim que se trata antes de uma história épica do Dicionário Grimm do que propriamente de um esboço biográfico dos seus idealizadores. Todavia, é com um fato decisivo na biografia dos irmãos que a narrativa se abre: em 1837, o príncipe de Hannover - um dos vários Estados alemães da época - revoga a constituição liberal promulgada alguns anos antes e sete professores da Universidade de Göttingen, os quais lhe haviam prestado juramento, realizam um ato de protesto. ${ }^{7}$ Entre esses estão os irmãos Grimm que, como os demais, são sumariamente despedidos e perdem todos os direitos civis. Jacob, mais veemente no protesto, é ainda expulso do principado e busca asilo na cidade de Kassel, pertencente ao vizinho Estado do Hesse, onde anos antes foram coligidos (e publicados entre 1812 e 1815) os contos maravilhosos que celebrizaram o nome Grimm. Três anos depois, os irmãos encontrarão asilo definitivo em Berlim, graças ao empenho da escritora romântica Bettina von Arnim junto ao imperador prussiano Frederico Guilherme IV. E se a atuação dessa incansável Bettina é narrada no capítulo dedicado à letra B, Grass faz o vocábulo "asilo" (Asyl) figurar já no título do primeiro capítulo de Grimms Wörter, tomando-o ainda como ensejo para enveredar polemicamente pela virulenta questão do asilo político na atual Alemanha. Esse capítulo, afinal, é todo ele dedicado ao A, "o mais nobre e primordial de todos os sons, ressoando plenamente do peito e da garganta, o som que a criança aprende em primeiro lugar e com mais facilidade a articular, e que os alfabetos da maioria das línguas colocam com razão em seu início", conforme traz o Dicionário Grimm na abertura do verbete A, redigido por Jacob em nada menos do que sete colunas!

No ócio forçado a que os irmãos se veem repentinamente lançados, chega então a proposta da editora Hirzel, em Leipzig, para a elaboração de um dicionário. Tem início desse modo uma empresa filológica em cujo desenvolvimento se espelharão as vicissitudes da história alemã ao longo de 123 anos. Pois ao acreditar nos primeiros tempos do projeto que poderiam concluir a tarefa em cerca de dez anos e em sete volumes, os irmãos subestimaram fragorosamente 
o que tinham pela frente: ao falecer em 1859, Wilhelm dera conta apenas da letra D; Jacob, mais disciplinado e dotado de incomum capacidade de trabalho, conseguiu vencer o A, B, C, E, assim como avançar bastante no F, falecendo em setembro de 1863 - conforme narrado no capítulo "Até que o fruto caia”, dedicado a essa letra - em meio à redação do verbete Frucht ("fruto" ou "fruta"). Mas os irmãos também pesquisaram de maneira assistemática, preenchendo centenas de fichas com verbetes para as demais letras do alfabeto. Todo esse material foi legado aos sucessores, cujo trabalho virou o século, atravessou a Primeira Guerra, a República de Weimar, os doze anos do nacional-socialismo (quando evidentemente foram eliminados do dicionário todos os vestígios judaicos), e ainda - agora de maneira "pan-germânica”, isto é, conduzido por filólogos da República Federal da Alemanha e da República Democrática Alemã - 15 anos da guerra fria, concluindo-se em janeiro de 1961 com a publicação do $32^{\circ}$ volume. ${ }^{8}$ E é uma das tristes ironias da história alemã que a conclusão do dicionário tenha praticamente coincidido com a construção, em agosto de 1961, do Muro de Berlim; fato tanto mais irônico considerando que o projeto do dicionário fora concebido também como estímulo cultural para a unificação dos Estados alemães - tarefa que, no plano material, estava sendo impulsionada pelo advento do trem de ferro (Eisenbahn, uma palavra recente, que Jacob reluta em incorporar ao dicionário) e pela expansão da malha ferroviária: "Desse modo", conforme escreve o narrador de Grimms Wörter, "a unidade da pátria, coisa que Jacob também desejava ardentemente, deveria ser fomentada, e superado o egoísmo medroso desse provincianismo de pequenos Estados". ${ }^{9}$

Reconstituir, portanto, a acidentada gênese do dicionário possibilita a Grass revisitar momentos cruciais da história alemã, não só os vividos pelos Grimm (como os acontecimentos de 1837 ou as turbulências revolucionárias em 1848), mas também aqueles com os quais se entrelaça sua própria biografia, marcada na adolescência pela aliciação ideológica da Juventude Hitlerista e, a partir dos anos 1960, pelo corajoso engajamento no movimento social-democrata, que o levou, por exemplo, a protagonizar as mais acirradas polêmicas durante o processo de reunificação alemã. Contudo, o elemento que organiza a imbricação de temporalidades e das trajetórias do narrador e dos irmãos Grimm são justamente as letras do alfabeto, como o A de "asilo" ou o B, tanto de Bettina como ainda de três ícones da social-democracia alemã: (August) Bebel, (Eduard) Bernstein e (Willy) Brandt.

É fácil imaginar as dificuldades que tal procedimento coloca a uma tradução, pois se nos casos onomásticos ou de palavras próximas ao latim verificase larga coincidência (como fructus: frubt, em antigo alto-alemão), na grande maioria dos vocábulos mobilizados por Grass o tradutor terá de valer-se de todos os recursos e de toda sorte de inventividades para tentar acompanhar os jogos linguísticos desse narrador a quem os críticos, certamente de modo fundamentado, costumam atribuir o adjetivo "barroco". ${ }^{10} \mathrm{O}$ próprio capítulo da letra F tem 
por fulcro palavras como Feuer ("fogo"), Forschung ("pesquisa", "investigação") ou Freibeit ("liberdade": o slogan Freie Fahrt für freie Bürger, "trajeto livre para cidadãos livres", é revelador da degradação sofrida pelo conceito de liberdade numa sociedade automobilística), enquanto o capítulo dedicado ao $\mathrm{K}$ - letra que Jacob, nos últimos anos de vida, já designara ao seu colaborador Hildebrand vem comandado, entre outras palavras, por Krieg, "guerra", cujo significado para a época dos Grimm, e ainda muito mais para os "tempos sombrios" de Grass, não é preciso enfatizar. Como nenhum outro livro desse autor, Grimms Wörter se caracteriza por uma profusão de paronomásias, aliterações e assonâncias, que ainda se intensificam nos 24 poemas incrustados nos capítulos. Mestre soberano da língua alemã, Grass constrói a narrativa manipulando ludicamente as sucessivas letras do alfabeto, e isso mesmo nos trechos em que reconstitui seus violentos embates ideológicos durante as décadas do pós-guerra. Nesse sentido, o livro parece concluir ao mesmo tempo uma trilogia autobiográfica, iniciada com o volume Beim Häuten der Zwiebel (Göttingen, 2006: Descascando a cebola, em tradução literal) e retomada em Die Box-Dunkelkammergeschichten (Göttingen, 2008: A caixa - histórias da câmara escura). ${ }^{11} \mathrm{E}$ para não poucos leitores serão justamente esses momentos autobiográficos os mais questionáveis de Grimms Wörter, pois via de regra Grass se apresenta então como alguém cujas posições e prognósticos políticos sempre estiveram corretos, decorrendo daí que a imagem que constrói de si mesmo ressinta-se por vezes da simpatia que soube dispensar às figuras de Wilhelm e, sobretudo, Jacob Grimm.

Por outro lado, mesmo o leitor mais refratário a Grass dificilmente deixará de admirar passagens como a que desdobra, ainda sob o império da letra $\mathrm{F}$, um encontro fictício entre dois pesquisadores (Forscher) contemporâneos: o inglês Charles Darwin, que demonstrou a ininterrupta mutação das espécies (sua origem e extinção por seleção natural, a sobrevivência mediante adaptação bemsucedida), e o alemão Jacob Grimm, que investigou a fundo deslocamentos de sons no corpo das palavras, perdas e mutações linguísticas, desde o sânscrito até o alemão de seu tempo. ${ }^{12} \mathrm{Na}$ ficção de Grass, o encontro não é bem-sucedido, pois ambos os pesquisadores se encontram demasiado imersos em suas respectivas ciências para poderem entrar em diálogo. Sendo assim, o narrador lamenta que no verbete Forschung Jacob só tenha oferecido espaço para as investigações linguísticas, literárias e históricas, deixando de lado as pesquisas nas ciências naturais, tal como praticadas por Darwin na distante Inglaterra ou, bem mais próximo do dicionarista, pelo grande naturalista Alexander von Humboldt. E uma vez que Darwin deparou nas Ilhas Galápagos com diferentes espécies de tentilhão - Fink, em alemão ( finco, no antigo alto-alemão) - o narrador observa, numa passagem cujo fino ludismo tende a perder-se na tradução, que também o tentilhão de Darwin poderia perfeitamente, ao lado de todos os demais tentilhões citados por Jacob no correspondente verbete, "ter encontrado alimento" no dicionário, pois - e aqui soa um antigo provérbio alemão - "quem deseja pegar tentilhões, tem primeiro de oferecer-lhes grãos". ${ }^{13}$ 


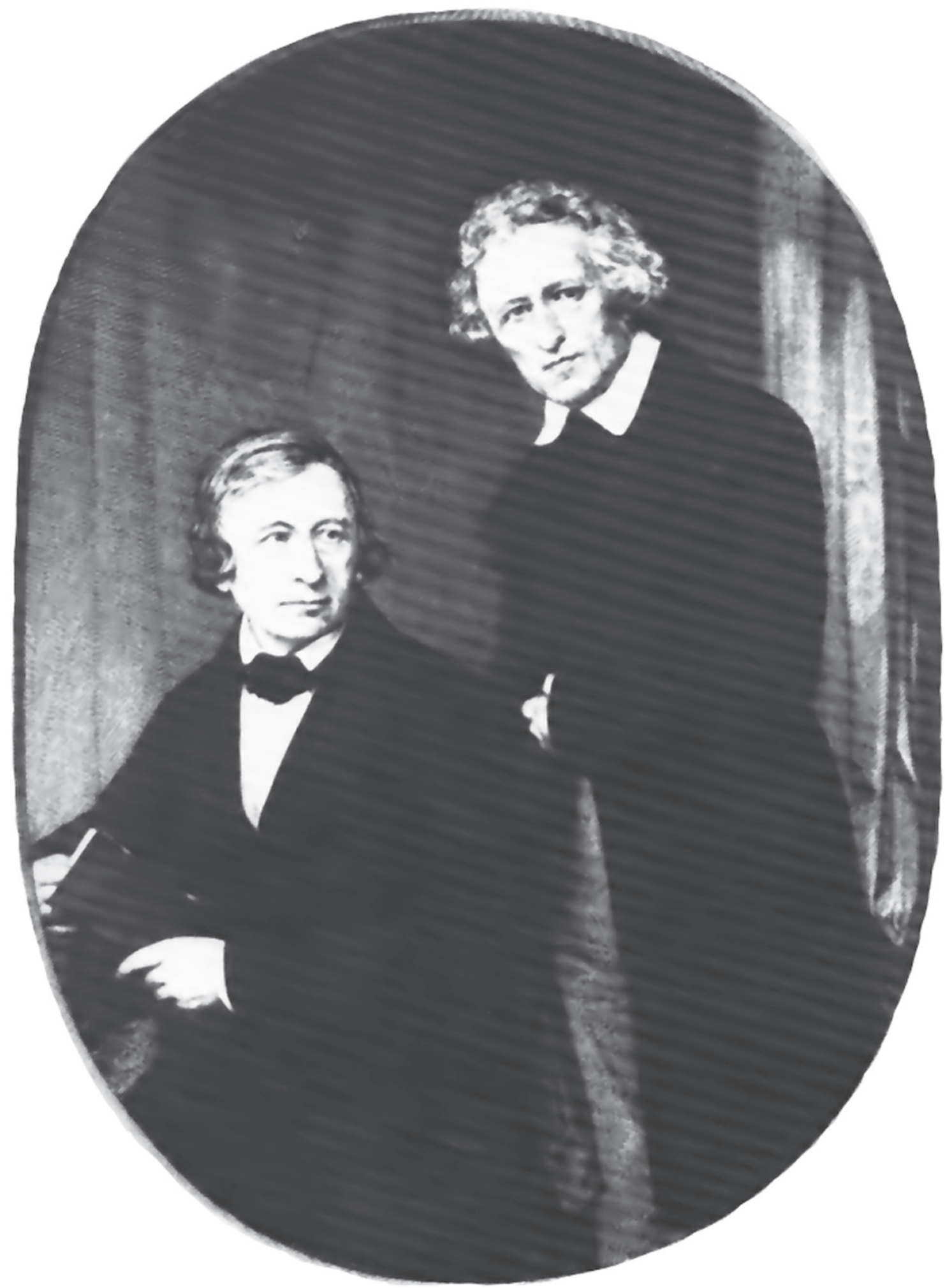

Foto de Wilhelm (sentado) e Jacob Grimm, feita em 1847 pelo fotógrafo alemão Hermann Biow (1804-1850). Jacob Grimm não gostou da foto: "Wilhelm está sentado como um doente e eu tenho o aspecto de alguém chamado para administrar a casa". 


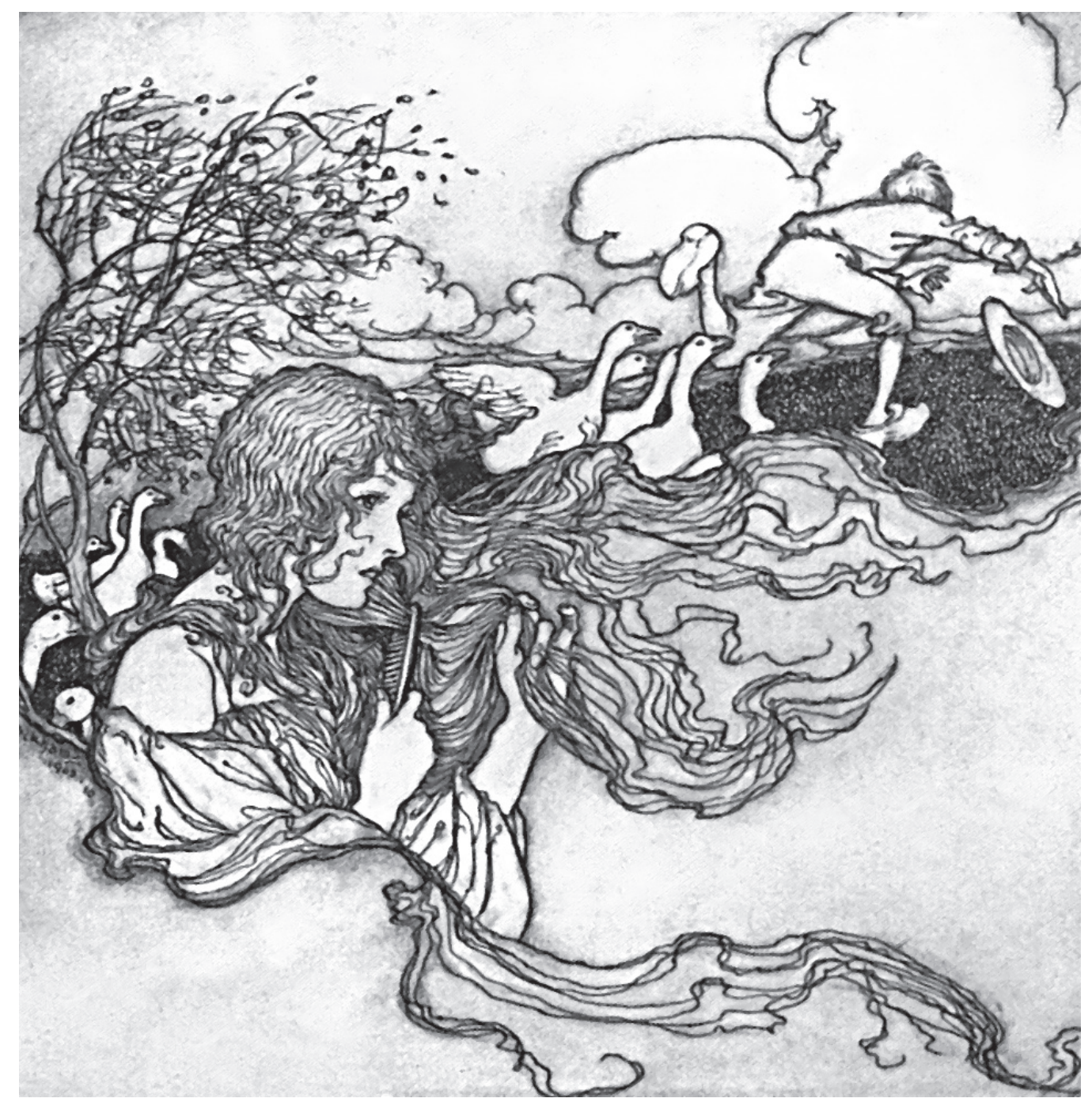

Ilustração (1914) deArthur Rackham (1867-1939) para o conto "A moça dos gansos".

Outro momento áureo do livro é a reconstituição do "Discurso sobre a velhice", proferido por Jacob na Academia Prussiana em janeiro de 1860, um "tema que bate secamente à porta, impõe-se e quer ir para o papel, ainda que seja com mão trêmula”, ensejando a Grass considerações sobre a própria velhice, como o isolamento causado pelo avanço da surdez, a crescente dependência de medicamentos (aqui são as estratégias da indústria farmacêutica, voltadas maciçamente para o lucro, que caem sob pesada crítica) e a aproximação da morte: "Ela ainda causa estranheza, mas vai se tornando mais familiar a cada noite de insônia. Eu sei: nela se pode confiar". Contudo, o teor do discurso - e Grass evidentemente acompanha esse movimento - caminha no rumo de uma celebração da velhice, a despeito de todas as suas carências e debilidades, que Jacob, aliás, de modo algum deseja relegar ao esquecimento: "Há uma contradição no fato de que, enquanto todas as pessoas desejam tornar-se velhas, elas no entanto 
não querem ser velhas. $\mathrm{O}$ ancião deveria sentir-se pleno de gratidão, uma vez que lhe foi dado marchar adiante até essa última etapa da vida". Tendo perdido parentes e amigos, é contudo natural que esse homem poupado pelo destino se sinta "só e abandonado, misturando assim alegria e tristeza"; mas do alto de suas experiências, ele pode também “olhar para trás com serena melancolia e, após o calor do dia, como que sentado no banco à porta de casa na fresca balsâmica do anoitecer, passar em revista a vida transcorrida".

E entre os frutos que ainda se colhem na velhice está também, na concepção de Jacob Grimm, a possibilidade de uma fruição mais intensa da Natureza, vivenciada sobretudo durante passeios solitários:

Já o menino gosta de perambular pelos campos em busca de ninhos de pássaros e borboletas, o jovem vagueia por bosques e prados com os sonhos e pensamentos voltados à amada, e o homem adulto - este é o que mais raramente encontra ócio para espairecer ao ar livre, pois centenas de compromissos e negócios prendem-no na cidade. Para o idoso, ao contrário, todo passeio se converte em caminhada prazerosa (Lustwandel), e mesmo que essa expressão alemã possa parecer retesada, aqui ela acertou na mosca. A cada passo que um tal caminhante dá, a cada bocado de ar puro que entra em seus pulmões, ele haure força vital e revigoramento. Nos anos de juventude a pessoa julga que se perde tempo com passeios; agora, porém, eles não trazem perda alguma mas puro ganho. Pois durante o passeio os pensamentos que a pessoa trouxe consigo continuam a sua marcha, sem empecilhos ou estorvos. Experimentei em mim mesmo, quando trilhas remotas me levavam por campos e plantações, que mesmo a passo redobrado acudiam-me excelentes ideias; e se em algum lugar de casa dúvidas ficaram pairando no ar, agora elas se resolviam na meditação peripatética. E topar a caminho com um conhecido querido! Como eu me alegrava do fundo da alma ao deparar-me, durante passeios no Tiergarten, com o meu irmão, quando repentinamente ele surgia do outro lado; em silêncio e meneando a cabeça, passávamos um pelo outro, e isso não pode mais acontecer.

As palavras do velho promeneur solitaire Jacob Grimm inspiram o velho Grass a falar também de seus passeios e caminhadas ao longo de um canal no norte da Alemanha ou pela floresta dinamarquesa de Ulvshale, de seus encontros e solilóquios (na falta de um irmão) consigo mesmo, o "duplo" de quem se torna, à medida que os anos avançam, cada vez mais difícil desviar-se. Mas também na reconstituição desse "discurso sobre a velhice", o narrador de Grimms Wörter dá rédeas largas à sua fantasia e coloca assim, entre os encanecidos ouvintes que nesse dia lotam a Academia Prussiana, não só a si próprio, mas também “imortais” como Fichte, Hegel, Herder, Leibniz, Schleiermacher. Tenta ainda proporcionar-lhes a companhia de Lutero (presente no dicionário com centenas de citações) e do bispo ariano Ulfila (ou Wulfila), que no século IV traduziu o Novo Testamento para o gótico, sistematizando esse idioma já extinto. A despeito, contudo, de todos os esforços, a sua fantasia confessa-se por fim impotente em enriquecer o seleto público com esses dois teólogos, tradutores e, para a ortodoxia católica, "notáveis hereges". 


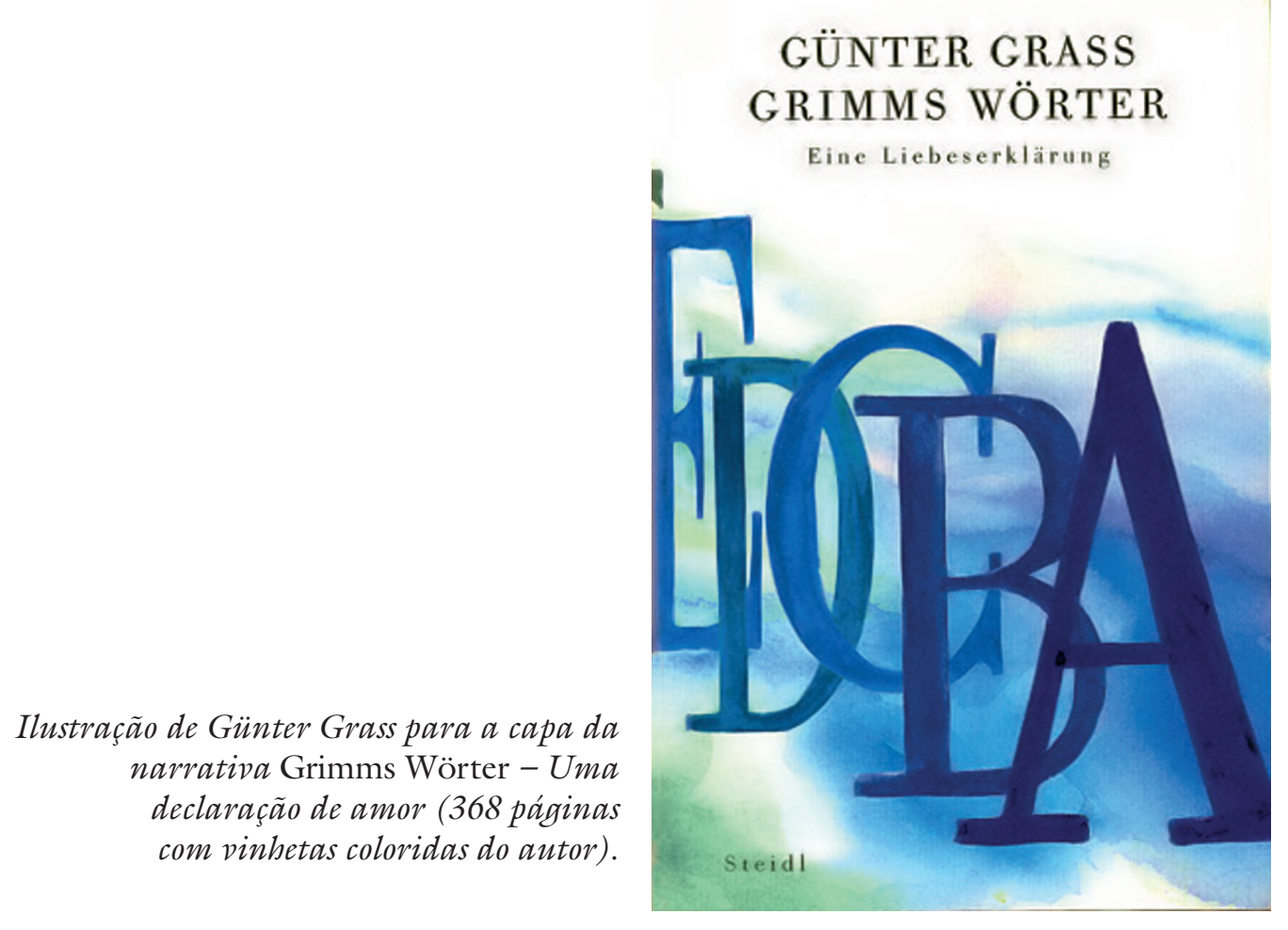

Salta aos olhos nesse episódio um procedimento que, desde a publicação do Tambor de lata em 1959, sempre foi característico da arte narrativa de Günter Grass, isto é, a imbricação entre elementos realistas e visionários. ${ }^{14} \mathrm{E}$ é para outro extraordinário momento modulado por esse mesmo hibridismo que Grimms Wörter conflui em seu último capítulo, no qual o tempo é suspenso (afinal estamos agora na letra Z, de Zeit, "tempo", e também de Ziel, "meta", "objetivo" ou "finalidade") e se mesclam as temporalidades. Transportando-nos para os dias imediatamente anteriores à construção do Muro que dividiu a Alemanha, o narrador fantasia um encontro com os inseparáveis irmãos no parque em que estes, durante os anos berlinenses, costumavam fazer passeios diários em busca de inspiração para o trabalho. A finalidade do encontro é comunicar-lhes que o dicionário acaba de ser concluído, graças ao esforço final de filólogos do leste comunista e do oeste capitalista. Eis, porém, que os Grimm acolhem a notícia com ceticismo, já descrentes da possibilidade de êxito na luta com palavras, pois que elas - ponderam os irmãos - sofrem contínuas mutações, geram novos sentidos e levam os antigos à extinção: portanto, diz agora Jacob em linguagem metafórica, "não há diques suficientemente fortes para a língua" que, como um rio, "vai sempre fluindo e transbordando das margens". Sobrevém então, exceção única no fluxo das transformações, a imagem da morte, "marco fronteiriço (Grenzstein) de todo poder, meta final (Zielpunkt) de toda aspiração", nas palavras do grande poeta barroco Andreas Gryphius, largamente representado no dicionário. 
Um melancólico acorde final, que parece ditado pela percepção da empresa vã e "sem fruto" que é lutar com palavras (para lembrar o poema "O lutador", de Carlos Drummond de Andrade), e ainda - também essa associação não será despropositada - pelo motivo barroco do desengaño. Mas teremos aqui a derradeira mensagem dessas "Palavras de Grimm" que o próprio autor comenta, em certo momento do capítulo dedicado à letra $\mathrm{K}$, como possivelmente o seu derradeiro trabalho de fôlego? A resposta seria não, pois se estivermos de fato diante do "canto de cisne" desse grande épico contemporâneo, então o velho Günter Grass estará se despedindo da arte da narrativa, antes de tudo, com uma comovida declaração de amor à língua alemã, e tomado ao mesmo tempo por um sentimento de gratidão que no capítulo da letra D (de Däumling) irradia-se para a mais célebre de suas personagens, o indestrutível liliputiano Oskar Matzerath que deve boa parte de sua existência a outro pequeno e obstinado herói dos irmãos Grimm, com o qual também o menino Günter Grass se deparou, no Teatro Municipal da antiga Danzig, por ocasião de uma vesperal natalina: ${ }^{15}$ "Ainda te lembras, Oskar, quão permanente foi o caminho que o Pequeno Polegar te apontou, quão resistente ele te fez, como te despachou para o que desse e viesse? Dize obrigado, Oskar, dize obrigado!”.

\author{
Er, der sich unter Großmutters Röcke duckte, \\ er, der aus Eigenwille treppab stürzte, \\ verdeckt unterm Tisch saß, \\ er, der im Innern einer Tribüne \\ den Takt diktierte und starre Ordnung in Tanz auflöste, \\ er, der den Schreck überdanernd \\ im Kleiderschrank hockte, \\ er, dem kein Keller zu duster, \\ kein Turmdach hoch genug, \\ ihm, der dem Bösen zu Diensten war, \\ ihm, dessen Stimme jegliches Glas durchdrang, \\ ihm, dem kein Dieb die Trommel betasten, \\ der aber einer Dame vom Zirkus nah, \\ ganz nah kommen durfte, \\ er, oberschlau, wollte nicht wachsen; \\ ich aber wuchs, dachte mich größer und größer, \\ wies jedem Ball die Delle \\ und allen Dingen den Schatten nach, \\ war Dorn im Fuß, Dolch in des Vaters Rücken \\ und schaute auf Fotos erwachsen drein. \\ Ach, Oskar, wäre ich doch wie Du \\ ein Däumling geblieben.
}


Ele, que se safou para baixo das saias da avó, que por teimosia jogou-se escada abaixo, permaneceu escondido sob a mesa, ele, que do interior de uma tribuna ditou o ritmo e desfez rígida ordem em dança, ele, que sobrevivendo ao terror, acocorou-se no guarda-roupa, ele, a quem nenhum porão foi demasiado escuro, nenhuma torre suficientemente alta, que esteve a serviço do maligno, ele, cuja voz transpassava todo vidro, a quem nenhum larápio pôde apalpar o tambor, mas que de uma dama de circo pôde chegar perto, pôde chegar muito, muito perto, ele, espertíssimo, não quis crescer; mas eu cresci, presumindo-me maior e maior, em cada bola demonstrei a sua deformidade e, em todas as coisas, a sua sombra, fui pedra no sapato, punhal nas costas do pai e em fotos fazia pose de adulto.

Ah Oskar, se como tu eu tivesse permanecido um Polegarzinho.

(Versos inseridos no capítulo dedicado à letra $\mathrm{D}$, inicial de "Pequeno Polegar" em alemão: Daumesdick, Daumerling, Däumeling ou simplesmente Däumling).

Notas

1 Letzte Ernte ist anf dem Halm ("Discurso sobre a velhice").

2 Der ist der glücklichste Mensch, der das Ende seines Lebens in Verbindung mit dem Anfang setzen kann (Maximen und Reflexionen, sentença 1064 na numeração estabelecida por Max Hecker em 1907).

3 A palavra alemã Märchen derivou da forma diminutiva do antigo substantivo Mär (ou Märe), com o significado, constituído no século XV, de "notícia ou história inverossímil". Märchen não possui correspondência exata em nenhuma língua: conte de fées, em francês; fairy-tale, em inglês; sprookje, em holandês. Em português, traduz-se geralmente por "conto de fadas", "conto das carochinhas", ou ainda "conto maravilhoso", o que talvez seja mais adequado, pois se Märchen nem sempre apresenta fadas ou carochas, jamais pode prescindir da dimensão do "maravilhoso". A palavra de fato ganha notoriedade e se impõe enquanto conceito de gênero no espaço linguístico alemão com os irmãos Grimm, que entre 1812 e 1815 publicam as suas coletâneas Kinder- und Hausmärchen [Contos maravilhosos para crianças e familias]. 
4 Trata-se do poema, escrito em 1919, O Falladah, die du hangest: “Oh, Falladah, que estás pendurado”. A narrativa dos irmãos Grimm (Die Gänsemagd, no original) retrabalhada por Brecht nesse poema já fora reconstituída por Heinrich Heine (17971856), como experiência marcante de sua infância, no capítulo XIV da mencionada sátira Deutschland. Ein Wintermärchen. Lembre-se também que o escritor Hans Fallada (na verdade, Rudolf Ditzen, 1893-1947) adotou esse pseudônimo a partir de dois contos dos Grimm: "A moça dos gansos" e "João Sortudo" (Hans im Glück).

$5 \mathrm{Na}$ coleção dos Grimm, as aventuras do Pequeno Polegar (Däumling, como se diz comumente) são narradas em dois contos em que o herói aparece com nomes diferentes, mas derivados ambos do substantivo masculino Daumen, "polegar": Daumesdick e Daumerling.

6 Grimms Wörter. Eine Liebeserklärung. Göttingen: Steidl-Verlag, 2010 (367p).

7 Essa revogação da constituição que entrara em vigor no Estado de Hannover em 1833 foi um dos primeiros atos de Ernst August I, empossado como novo soberano após a morte, no dia 20 de junho de 1837, de seu irmão Wilhelm IV (William Henry), rei da Grã-Bretanha e de Hannover, que desde 1714 se encontravam sob o vínculo da chamada "União Pessoal” (Personal Union). Conhecidos como os "sete de Göttingen", os outros professores que, ao lado dos irmãos Grimm, articularam o protesto contra a revogação foram os historiadores Friedrich Christoph Dahlmann e Georg Gottfried Gervinus, o jurista Wilhelm Eduard Albrecht, o teólogo e orientalista Georg Heinrich August Ewald e o físico Wilhelm Weber.

8 A edição online do Dicionário Grimm, digitalizada por uma equipe da Universidade de Trier sob a coordenação do germanista Kurt Gärtner, pode ser acessada sob o endereço eletrônico: <http://www.dwb.uni-trier.de/>

9 Observe-se que, no Manifesto comunista (1848), também Marx e Engels saúdam o advento do trem de ferro e de uma densa malha ferroviária como poderoso fator de integração e unificação (mas especificamente do movimento proletário): "E a união, para a qual os burgueses da Idade Média, com seus caminhos vicinais, necessitaram de séculos, os proletários modernos, com as estradas de ferro, executam-na em poucos anos" (Manifesto comunista, trad. Marcus Mazzari, São Paulo: Hedra, 2010, citação à p.70 - tradução publicada originalmente na Revista Estudos Avançados, n.34, p.7-46, set.- dez. 1998 [citação à p.17]).

10 Em diversas oportunidades, o próprio Grass enfatizou os seus vínculos e afinidades com a literatura do barroco. A bela narrativa de 1979 Das Treffen in Telgte [O encontro em Telgte], cuja ação se passa no verão de 1647, presta significativa homenagem a poetas, dramaturgos, narradores e mesmo editores desse período, em especial ao autor do Simplicissimus, Hans Jakob Christoffel von Grimmelshausen (1622-1676).

11 O primeiro volume, que abarca os anos entre 1939 e 1959, quando surge O tambor de lata e Grass se muda com a família de Paris para Berlim, foi publicado no Brasil com o título Nas peles da cebola (trad. Marcelo Backes, Rio de Janeiro: Record, 2007). Já o volume subsequente $A$ caixa - ainda sem tradução brasileira, mas publicado em Portugal em 2009 pela editora Casa das Letras, que também já anuncia a versão portuguesa de Palavras de Grimm - estende-se pelo período de 1959 a 1999 e concentra-se sobretudo nas relações familiares (como o convívio com seis filhos, além de dois outros de sua segunda mulher), iniciando-se assim com as palavras: "Era uma vez um pai que, por ter ficado idoso, reuniu seus filhos e filhas". No título, contudo, Grass alude 
à velha "caixa" fotográfica da amiga que o acompanhou por várias décadas e a quem o livro é dedicado, a fotógrafa Maria Rama (1911-1997).

12 Jacob Grimm conhecia vários idiomas, não só os clássicos, mas também modernos, como o dinamarquês e o sérvio. Em relação ao primeiro, levantou a tese de que se tratava antes de um dialeto alemão, o que abalou sensivelmente sua imagem na Dinamarca - ao contrário do prestígio de que sempre gozou na França, mesmo após ter recusado convite para assumir uma cátedra em Paris (o motivo foi o seu descontentamento com o resultado das negociações que travou, na capital francesa, para a devolução de obras de arte e livros confiscados durante a ocupação napoleônica). Quanto ao idioma sérvio, Jacob traduziu e prefaciou a gramática elaborada pelo filólogo Vuk Stefanović Karadžić (1787 - 1864) assim como várias canções populares sérvias (recolhidas pelo mesmo Karadžić), as quais encantaram Goethe e o levaram a comentá-las em uma série de textos no último decênio de sua vida (justamente no período em que desenvolvia a concepção de "literatura universal").

13 Ou seja, a passagem sugere que no verbete já haveria ceva suficiente para capturar também o tentilhão de Darwin. Além disso, no original Grass faz ressoar o sentido figurado que a língua alemã empresta a algumas designações de tentilhão arroladas por Jacob Grimm, como Mistfink, algo como "tentilhão-porcalhão": Weshalb im Wörterbuch, weil Darwin auf den Galapagosinseln verschieden gearteten Finken begegnet war, gleich nach dem Fink, und dem althochdeutschen finco folgend, inmitten der Aufzühlung blutfink, brandfink, distelfink, mistfink, durchaus der Darwinfink hätte Nabrung finden können, denn "wer finken fangen will, musz ibnen zuvor körnen" (p.239). Nesta passagem, as quatro espécies de tentilhão - blutfink, brandfink, distelfink, mistfink, em tradução literal: tentilhão-sangue, tentilhão-fogo, tentilhão-cardo (Distelfink se traduz também por pintassilgo), tentilhão-esterco - assim como o provérbio (entre aspas) são citados conforme grafados por Jacob Grimm, isto é, com os substantivos em letra minúscula. No geral, os irmãos Grimm postulavam um emprego extremamente parcimonioso da letra maiúscula.

14 Já em 1963, Grass fez a seguinte declaração no contexto de uma entrevista à revista Spiegel: "Eu preciso descrever o fantástico da maneira mais exata possível, preciso carregá-lo com o máximo de realidade para que ele não se dissipe no ar, não se volatilize". Abordei o emprego dessa técnica narrativa em $O$ tambor de lata (assim como nas duas outras obras da Trilogia de Danzig) no capítulo "Formas de integração entre Ficção e História" (p.117-131), no estudo Romance de formação em perspectiva histórica - O tambor de lata de Günter Grass (São Paulo: Ateliê Editorial, 1999).

15 Guardadas as proporções entre $O$ tambor de lata (mesmo sendo um dos maiores romances do século XX) e o Fausto, opus magnum da literatura alemã, essa vivência de infância relatada pelo próprio Grass pode ser relacionada ao encontro do menino Goethe com o doutor Fausto do teatro de marionetes, conforme narrado em sua autobiografia Poesia e verdade (segunda parte, livro 10).

RESUMO - Este ensaio aborda a narrativa Grimms Wörter [Palavras de Grimm], publicada por Günter Grass em agosto de 2010, pouco antes de completar 83 anos. Wilhelm e Jacob Grimm são suas personagens principais e o tema gira em torno dos esforços despendidos pelos irmãos para elaborar um grande dicionário da língua alemã, concluído apenas em 1961 com a publicação do $32^{\circ}$ volume. Organizando os capítulos do 
livro (e também a estrutura narrativa) pelas letras do alfabeto, Grass presta comovida homenagem ao trabalho filológico de Wilhelm e Jacob Grimm, ao mesmo tempo que faz uma declaração de amor à língua alemã. Ao mostrar ainda de que modo 123 anos da história alemã se refletem na intrincada gênese do dicionário, o narrador toma episódios fundamentais da vida dos irmãos Grimm como ensejo para reconstituir estações de sua própria biografia política e artística. Na perspectiva desse entrelaçamento de trajetórias, o ensaio privilegia uma passagem do capítulo dedicado à letra "D" (de Düumling: Pequeno Polegar, em alemão) para ressaltar a influência que um dos mais célebres heróis dos irmãos Grimm teve sobre a concepção de Oskar Matzerath, o eu narrador do romance $O$ tambor de lata. Estabelece-se assim um arco entre a narrativa Grimms Wörter e o romance que proporcionou notoriedade mundial ao jovem Günter Grass.

PALAVRAS-CHAVE: Günter Grass, Irmãos Grimm, Deutsches Wörterbuch, Língua e história alemãs, Velhice, Pequeno Polegar, Oskar Matzerath.

ABSTRACT - This essay discusses the narrative Grimms Wörter [Words of Grimm] published by Günter Grass in August 2010, just before his eighty-third birthday. Wilhelm and Jacob Grimm are his main characters, and the theme centres on the efforts of the brothers to elaborate a great dictionary of the German language, which was only completed in 1961 with the publication of the thirty-second volume. Organizing the chapters of the book (and also the narrative structure) by the letters of the alphabet, Grass makes a moving tribute to the philological work of Wilhelm and Jacob Grimm and a declaration of love for the German language. He also shows that 123 years of German history are reflected in the intricate genesis of the dictionary, using important episodes in the lives of the Grimm Brothers to reconstitute the periods of his own artistic and political autobiography. Examining this fusion of trajectories, the essay highlights a passage from the chapter on the letter "D" (Däumling: Tom Thumb) to emphasize the influence that one of the best-known heroes of the Grimm Brothers had on the conception of Oskar Matzerath, the first person narrator of the novel The Tin Drum. Thus a link is established between Grimms Wörter and the novel which made the young Günter Grass world famous.

KEYWORDS: Günter Grass, Grimm Brothers, Deutsches Wörterbuch, German Language and History, Old Age, Tom Thumb, Oskar Matzerath.

Marcus V. Mazzari é professor de Teoria Literária e Literatura Comparada na USP, tradutor e também autor, entre outros, de Labirintos da aprendizagem - Pacto fáustico, romance de formação e outros temas de literatura comparada (Editora 34, 2010). Elaborou os prefácios, comentários e notas aos volumes Fausto I (Editora 34, 2004 edição revisada e ampliada: 2010) e Fausto II, de Goethe (Editora 34, 2007), em tradução de Jenny Klabin Sega. @- mazzari@usp.br

Recebido em 7.2.2011 e aceito em 22.2.2011. 